\title{
Time to stop the exploitation of free academic labour
}

Jonathan P. Tennant

\section{Email: jon.tennant.2@gmail.com}

IGDORE, UK

Keywords: Peer Review, Scholarly Publishing, Plan S, Quality Control, Professional Services

\section{https://orcid.org/0000-0001-7794-0218}

\begin{abstract}
Commercial publishing houses continue to make unbounded profits while exploiting the free labour of researchers through peer review. If publishers are to be compensated financially for the value that they add within a capitalist system, then all others who add value should be similarly, including reviewers. I propose that peer review should be included as a professional service by research institutes in their contracts with commercial publishers. This would help to recognise the value of peer review, and begin to shape it into a functional form of quality control.
\end{abstract}

Historically, peer review was considered to be an altruistic duty for academics, as scholarly publishing was largely a within-community and non-profit enterprise overseen by scholarly societies (1). However, this altruism is easy to exploit. We know from limited information that a small proportion of the research community performs the majority of reviews (2-4); so, although it might be generally altruistic for the wider community, it is certainly more beneficial for some than others. Commercialisation of this process in the post-WW2 era led to the hi-jacking and exploitation of this altruism for profiteering purposes (5). Societies became drawn into this with a desire to remain 'competitive' within an increasingly neoliberal academia. Eventually, institutes, researchers and funders all became locked into this system due to an increasing dependency on journals, which had become purposed for the unholy trinity of prestige, information, and assessment. This imbalance is weighted against postcolonial countries. All of the major publishing houses are operated primarily from western 
Europe, which has far more resource potential than developing nations. Because researchers from almost all around the world are forced in various ways to provide these services for the major 'international' publishers, it represents further exploitation of this inequity. Despite having less infrastructure and funding than developed nations, developing countries are held to the same standards and scholarly communication expectations, further reinforcing the global imbalance in knowledge acquisition and production (6).

Researchers and research institutes now have a strange relationship with the commercial publishing sector. Some are addicted to the system simply because their careers depend so greatly on it. Others are wedded to journals and even defend them, precisely because their careers have benefited from their existence. Career progression, awards, and reputation are all things primarily built based upon ones' publication record (7). Over time, this has created a strange blend of nonchalance, apathy, and elitism towards scholarly publishing from much of the research sector. Combined with a view that "it has always been this way", led to a system of cultural inertia where we still rely now on 350-year-old technologies and the processes embedded with them, including peer review. The combined result of this attitude problem, the stagnation in change, and the tight system-lock in is that academic labour is now exploited in a number of different dimensions to support a variety of non-profit and for-profit ventures.

Now, there are a number of high-level changes happening in the world of scholarly publishing. For example, Plan S originating in Europe (8), and recent discussions around a new Executive Order in the USA that could accelerate public access to knowledge. However, virtually all of these high-level changes have ignored, either intentionally or passively, the critical issue of exploitation of free labour in the scholarly publishing sector. Even more strangely, many of these national and institutional policies now mandate their researchers to publish in journals operated by commercial publishing houses. But at the same time, they do not reimburse researchers for doing this in any way, or fairly. Nor do they ask those commercial publishers to compensate their employees for out-sourcing their labour. Instead, many of these major political changes in the last decade seem to be focused more on preserving the revenue streams of the existing publishing system, rather than creating a fair and competitive market (9). Because of its low apparent financial value, peer review activities are consistently unrecognised and undervalued in evaluation procedures, which creates a strange tension as 
they are simultaneously considered to be a critical element of scholarly activities and an expected part of the job for academics (10). This is especially critical due to the increase in non-tenure jobs in academia, which are no longer fairly compensated to counterbalance the exploitation of free labour. Fair compensation must be a critical part of future discussions on scholarly communication. It cannot be divorced from issues about creating a healthier academic culture (11).

\section{Peer review is a professional service}

With this evolutionary shift towards a more commercial system in mind, why is providing pro bono services to those commercial publishers still seen as a duty or responsibility? It makes sense based on a historical legacy of duty to one's community, but not now that it is dominated by a powerful commercial empire (12). How have academics been gullible enough to fall for this scheme, at the expense of billions of dollars a year, and the outsourcing of ownership of our scholarly legacy? The duty that scholars have now is to make their work available to anyone who wants it: universal Open Access, so that knowledge serves the people and not profits (13).

This is a hypocrisy embedded in the core of our scholarly production and communication systems. Commercial publishers argue that they provide sufficient "added-value" to be financial compensation for their activities. If this is true, then by extension all other providers in then chain who provide value should be similarly compensated for their labour. The biggest publishers are multi-national corporations, often with billions of dollars in annual revenue and hefty net profit margins (12). As part of a capitalist system, they must appropriately compensate the work that supports them as a matter of principle, including retroactively reimbursing all reviewers for their work as labourers. Within scholarly publishing, on the supply side we have the funders and authors, and in the 'production' side, the editors, typesetting staff, administrative staff, and all of the others needed to support the industry. Besides authors, peer reviewers are the only stakeholder group not to be financially reimbursed for their labour. Peer review is a professional service that, and there should be legal requirements for it. This includes, at a bare minimum, financial reimbursement, authoritative standards and checklists, and transparency and objectivity. There is absolutely no way that peer review can maintain its standing as a professional form of quality control without these things (14). 
We know that the average income generated is $\$ 5000$ per article (15), and none of it goes to those who provide the most work: peer reviewers, editors, and authors do not receive commensurate compensation for the free labour that they provide to those publishers. They typically provide the invaluable services that keep the publishing machine rolling: writing, type-setting (e.g., with LaTex), reviewing for technical accuracy, proofing, copy-editing, archiving, and distributing; all things that are highly-skilled and time-consuming. On the other hand, researchers often acknowledge that we seem to pay publishers for the Herculean effort of introducing problems into our papers: broken links, formatting issues, delays to publication, and useless proprietary article rendering formats.

Any researcher can calculate how much financial value their peer review efforts are, simply based on the number of hours spent on it compared to their salary. On average, a typical researcher spends 2-6 hours reviewing a research paper, depending on the type of article $(16,17)$. Around 3 million peer-reviewed English-language articles are now published in STM journals each year (18). The total and unpaid cost of reviewers' time globally each year has been estimated at $£ 1.9$ billion, a lower-bound that does not account for the laborious rejectresubmit cycle $(19,20)$. This unpaid work is foundational to a $\$ 25.7$ billion/year industry $(18)$, which would not be able to exist without such services.

At its core, peer review is a form of quality control (QC). QC protocols in almost any other industry and standardised and considered to be a form of professional consultancy and labour. The scholarly publishing industry is unique in that its primary form of $Q C$ is neither standardised nor compensated for. Being invited to review a paper is an explicit acknowledgement of professional expertise in a sector, and must be treated that way. Graduate students often get paid extra for things like grading papers and exams, so why should it be different for peer review? If a researcher is commissioned by a company for professional consulting services, then why is peer review any different? All other actors in the publishing system get appropriate financial compensation, so why not peer reviewers? If peer review is an altruistic activity that the community benefits from, then why are publishers the only ones who reap financial reward for it? If an academic does any other form of work, including writing news articles, books, or consultation, they get paid for it, so why not peer review? 
Institutes pay researchers to do research, but many researchers are independent or are salaried via other means. Peer review takes away time from research, and the value is capitalised on by a third-party at the expense of an institute. I doubt that any institute would be particularly happy in knowing the total amount of unfinanced labour their staff give out to for-profit entities each year. In job adverts and descriptions for researchers, it very rarely says anything along the lines of "perform professional services for third-party commercial entities without any form of compensation." Because of this, peer review work is often done outside of professional hours as a form of unpaid overtime. This is an increased burden on an already over-worked community. If reviewers stopped reviewing, their salaries would remain exactly the same, and they would get more personal work done for their employers and funders. Reviewers already get 'rewarded' in a way as they are able to list their reviewer activities on their CV, or on platforms such as Publons. However, performing a professional service for the potential perception of prestige or privilege is akin to the 'do it for the publicity' arguments that plague the art and media industries.

Peer review is not dependent on the publishing industry. If the private sector did not exist, peer review would still function through existing alternatives. Yet, the entire publishing sector is utterly dependent on peer review to function. This represents an incredible asymmetry in power, and yet the value flow is on the opposite direction. If all researchers decided in synchrony to stop peer reviewing, the entire publishing industry would collapse. Or at least, the substantial revenues and profits that the private publishing sector make could be greatly reduced. This is a collective action problem, but such a simple notion indicates precisely where the core value in the process should lie.

\section{A potential solution}

Simply, universities and research institutes should start directly charging publishers for services. Contracts already exist between universities and publishers, often now termed 'transformative agreements' in the wake of Plan S. There is no reason why peer review, as a professional service, should not be bundled into these contracts. For example, universities could agree that their staff will provide a certain number of reviews for a publisher in exchange for a commensurate discount on subscriptions or OA. This can be tied directly into 'transformative agreements' as a powerful form of negotiation leverage. If publishers do not 
lower their costs and provide financial reimbursement, then universities can stop those publishers from exploiting their staff for free labour. Thus, there is a strong incentive for newly forming library and university consortia to support these initiatives as a form of collective action (21). This does not to be applied to all publishers, but can be selectively targeted; for example, explicitly at the 'big-five' publishing houses, or only commercial or for-profit ventures, or only those that are clearly able to afford it by having excessive profit margins. Ultimately, the solution is focused around universities or learned societies 'sub-contracting' their employees' or members' labour.

Additional potential side effects of this are possible. Sharing the peer review load more fairly and evenly across the research community by diversifying and expanded the reviewer pool is one. As a result of this, we might see the increasing innovation and operationalisation of peer review; for example, through systems of micro-contributions and version control, which would reduce the burden on any individual researcher (10).

\section{What is stopping this}

One argument is that authors already receive appropriate credit for their work in a variety of forms; many, but not all, already receive a salary or grant from their funders or respective institutes. If publishers were to start paying reviewers, including indirectly, they are not going to willingly do so if this translates into a loss in their net income and profits. As such, publishers would likely begin to lump these costs into existing contracts in order to cover them, thus providing a further burden on researchers and institutes. This could potentially damage smaller publishers with less revenue too, who might be unable to afford paying their reviewers. However, if a publisher cannot support itself without free volunteer labour, then it has a severe business model issue. The idea we should continue to support commercial entities with uncompensated labour just to protect their functionality is unheard of in any other industry. If a publisher were to increase their prices to compensate for paying reviewers, this would simply expose that they have not been operating fairly historically, and that the costs for the relatively value of services they offer is disproportionate.

\section{References}


1. Fyfe A, Coate K, Curry S, Lawson S, Moxham N, Røstvik CM. Untangling Academic Publishing. A history of the relationship between commercial interests, academic prestige and the circulation of research. 2017;26.

2. Fox CW, Albert AYK, Vines TH. Recruitment of reviewers is becoming harder at some journals: a test of the influence of reviewer fatigue at six journals in ecology and evolution. Research Integrity and Peer Review. 2017 Mar 8;2(1):3.

3. Gropp RE, Glisson S, Gallo S, Thompson L. Peer Review: A System under Stress. BioScience. 2017 May 1;67(5):407-10.

4. Kovanis M, Porcher R, Ravaud P, Trinquart L. The Global Burden of Journal Peer Review in the Biomedical Literature: Strong Imbalance in the Collective Enterprise. PLOS ONE. 2016 Nov 10;11(11):e0166387.

5. Buranyi S. Is the staggeringly profitable business of scientific publishing bad for science? [Internet]. The Guardian. 2017 [cited 2020 Mar 6]. Available from: https://www.theguardian.com/science/2017/jun/27/profitable-business-scientificpublishing-bad-for-science

6. Posada A, Chen G. Inequality in Knowledge Production: The Integration of Academic Infrastructure by Big Publishers. In: Cha L, Mounie P, editors. ELPUB 2018 [Internet]. Toronto, Canada; 2018 [cited 2019 Jan 24]. Available from: https://hal.archivesouvertes.fr/hal-01816707

7. McKiernan EC, Schimanski LA, Nieves CM, Matthias L, Niles MT, Alperin JP. Use of the Journal Impact Factor in academic review, promotion, and tenure evaluations [Internet]. PeerJ Inc.; 2019 Apr [cited 2019 Apr 19]. Report No.: e27638v2. Available from: https://peerj.com/preprints/27638

8. Johnson R. From coalition to commons: Plan S and the future of scholarly communication. Insights. 2019 Jan 30;32(1):5.

9. Tennant J, Brembs B. RELX referral to EU competition authority [Internet]. Zenodo; 2018 Oct [cited 2018 Dec 12]. Available from: https://zenodo.org/record/1472045\#.XBEeoWjOIPY

10. Tennant JP. The state of the art in peer review. FEMS Microbiol Lett [Internet]. 2018 Oct 1 [cited 2019 Jan 10];365(19). Available from: https://academic.oup.com/femsle/article/365/19/fny204/5078345

11. Abbott A. Stress, anxiety, harassment: huge survey reveals pressures of scientists' working lives. Nature. 2020 Jan 15;577(7791):460-1.

12. Larivière V, Haustein S, Mongeon P. The Oligopoly of Academic Publishers in the Digital Era. PLOS ONE. 2015 Jun 10;10(6):e0127502. 
13. Tennant JP, Waldner F, Jacques DC, Masuzzo P, Collister LB, Hartgerink ChrisHJ. The academic, economic and societal impacts of Open Access: an evidence-based review. F1000Research. 2016 Sep 21;5:632.

14. Tennant J, Ross-Hellauer T. The limitations to our understanding of peer review. 2019 Aug 29 [cited 2020 Mar 7]; Available from: https://osf.io/preprints/socarxiv/jq623/

15. Schimmer R, Geschuhn KK, Vogler A. Disrupting the subscription journals' business model for the necessary large-scale transformation to open access. $2015 \mathrm{Apr} 28$ [cited 2019 Feb 2]; Available from:

https://pure.mpg.de/pubman/faces/ViewltemOverviewPage.jsp?itemld=item_214896 1

16. Rooyen S van, Godlee F, Evans S, Black N, Smith R. Effect of open peer review on quality of reviews and on reviewers'recommendations: a randomised trial. BMJ. 1999 Jan;318(7175):23-27.

17. Riley $B J$, Jones R. Peer review: acknowledging its value and recognising the reviewers. Br J Gen Pract. 2016 Dec;66(653):629-30.

18. Johnson R, Watkinson A, Mabe M. The STM Report: An overview of scientific and scholarly publishing. International Association of Scientific, Technical and Medical Publishers. 2018;

19. Network RI. Activities, costs and funding flows in the scholarly communications system in the UK. Research Information Network. 2008;

20. Hide B. How much does it cost, and who pays? The global costs of scholarly communication and the UK contribution. Serials. 2008;21(3).

21. Tennant JP. Democratising knowledge: A report on the scholarly publisher Elsevier [Internet]. Education International; 2018. Available from: https://bit.ly/2PPjwRK 